\title{
Pitch and Loudness from Tinnitus in Individuals with Noise-induced Hearing Loss
}

\author{
Leticia Sousa Flores ${ }^{1}$ Adriane Ribeiro Teixeira ${ }^{1}$ Leticia Petersen Schmidt Rosito ${ }^{2}$ \\ Bruna Macagnin Seimetz ${ }^{3}$ Celso Dall'Igna ${ }^{4}$
}

1 Department of Health and Human Communication, Universidade Federal do Rio Grande do Sul, Porto Alegre, Rio Grande do Sul, Brazil

${ }^{2}$ Department of Otolaryngology - Head and Neck Surgery, Hospital de Clínicas de Porto Alegre, Porto Alegre, Rio Grande do Sul, Brazil

3 Post-Graduate Program in Child and Adolescent Health, Universidade Federal do Rio Grande do Sul, Porto Alegre, Rio Grande do Sul, Brazil

${ }^{4}$ Department of Ophthalmology and Otorhinolaryngology,

Universidade Federal do Rio Grande do Sul, Porto Alegre, Rio Grande do Sul, Brazil

Int Arch Otorhinolaryngol 2016;20:248-253.

\begin{abstract}
Address for correspondence Adriane Ribeiro Teixeira, MD, PhD, Department of Developmental Psychology and Personality, Universidade Federal do Rio Grande do Sul, Rua Ramiro Barcelos, 2600 Instituto de Psicologia da UFRGS, Porto Alegre, Rio Grande do Sul 90035003, Brazil (e-mail: adriane.teixeira@gmail.com).
\end{abstract}

\begin{abstract}
Introduction Tinnitus is one of the symptoms that affects individuals suffering from noise induced hearing loss. This condition can be disabling, leading the affected individual to turn away from work.

Objective This literature review aims to analyze the possible association between gender and tinnitus pitch and loudness, the degree of hearing loss and the frequencies affected in subjects with noise-induced hearing loss.

Methods This contemporary cohort study was conducted through a cross-sectional analysis. The study sample consisted of adults with unilateral or bilateral tinnitus, who had been diagnosed with noise-induced hearing loss. The patients under analysis underwent an otorhinolaryngological evaluation, pure tone audiometry, and acuphenometry.

Results The study included 33 subjects with noise-induced hearing loss diagnoses, of which 22 (66.7\%) were men. Authors observed no statistical difference between gender and loudness/pitch tinnitus and loudness/pitch in subjects with bilateral tinnitus. Authors found an inverse relation between tinnitus loudness with intensity greater hearing threshold and the average of the thresholds and the grade of hearing loss. The

Keywords tinnitus pitch showed no association with higher frequency of hearing threshold.

- hearing loss

- noise-induced Conclusion Data analysis shows that, among the individuals evaluated, the greater the hearing loss, the lower the loudness of tinnitus. We did not observe an association

- tinnitus between hearing loss and tinnitus pitch.
\end{abstract}

\section{Introduction}

Noise-induced hearing loss (NIHL) is a reduction in high frequencies hearing caused by exposure to elevated levels of sound pressure for prolonged periods of time. ${ }^{1}$ According to the World Health Organization (WHO), ${ }^{2}$ noise is the second type of pollution that causes the most diseases in the world, whereas NIHL is one of the most common occupational diseases. This hearing loss is irreversible, permanent and characterized as sensorineural, bilateral, and symmetrical. received

April 23, 2015

accepted

June 28, 2015

published online

August 24, 2015
DOI http://dx.doi.org/

10.1055/s-0035-1562935.

ISSN 1809-9777.
Copyright $\odot 2016$ by Thieme Publicações License terms

Ltda, Rio de Janeiro, Brazil
(ब)(1) $\Theta$ 
Initially, it affects frequencies from $4000 \mathrm{~Hz}$ to $6000 \mathrm{~Hz}$, with recovery at the $8000 \mathrm{~Hz}$ threshold. As the years go by, other frequencies become affected, although thresholds generally remain below 75dBNA for high frequencies and 40dBNA for low frequencies. $1,3,4$

Together with hearing loss, individuals with NIHL usually present tinnitus. ${ }^{5}$ Tinnitus is defined as a conscious perception of a hearing sensation in the absence of a corresponding external stimulus. ${ }^{6}$ This sensation can be abrupt, although, in most cases, it is insidious. ${ }^{7}$

There is still a lack of data pertaining to the incidence of tinnitus among the Brazilian population, but it is believed to be very similar to that found in the Unites States, which ranges from 1 to $32 \%$ of the population. Among these individuals, tinnitus has no interference in daily life for $80 \%$ of cases, while in $15 \%$ of cases, there is some consequence, and in $5 \%$, tinnitus can be disabling. ${ }^{8}$

One study performed with individuals with NIHL found a tinnitus prevalence of $48 \%$. Furthermore, it confirmed that, for each year in the life of a worker studied, the chances of having tinnitus increases by an average of $3.4 \%$ and $2.5 \%$ in the left and right ears, respectively. Moreover, the authors concluded that there is a dose-response relationship between hearing loss and tinnitus, or, in other words, the greater the hearing loss the greater the tinnitus. ${ }^{9}$

Some research studies analyze the prevalence of tinnitus in specific groups. ${ }^{9-13}$ However, there are few that analyze the characteristics of tinnitus through psychoacoustic means in workers with NIHL. ${ }^{5,14-17}$ Thus, the need for studies about this theme, specifically with Brazilian individuals, justifies the importance of this research. Along these lines, the objective of the study is to analyze the existence of an association between tinnitus pitch and loudness and the types of variables, degree of loss, and the frequencies affected in individuals with NIHL.

\section{Methods}

A cross sectional cohort study was performed. Included in the study, were adult individuals of both genders, having unilateral or bilateral tinnitus, treated at the tinnitus outpatient ward of the hospital, with a NIHL medical diagnosis. It should be noted that only individuals who refer to discomfort caused by tinnitus receive treatment in this outpatient ward.

The authors excluded from the sample individuals who did not agree to participate voluntarily in the research study, not signing the Term of Free and Informed Consent, or that did not carry out all of the evaluations provided in the project, or those that filled out admittance forms with incomplete data, or did not have an NIHL diagnosis.

Initially, the group underwent otorhinolaryngologic evaluations with anamnesis and otoscopy with the purpose of identifying probable trigger factors for tinnitus, as well as confirm their ears' conditions to carry on with the exams.

Next, the individuals went through tone threshold audiometry in sound-treated booths to survey conduction thresholds of the air $(250 \mathrm{~Hz}, 500 \mathrm{~Hz}, 1000 \mathrm{~Hz}, 2000 \mathrm{~Hz}, 3000 \mathrm{~Hz}$, $4000 \mathrm{~Hz}, 6000 \mathrm{~Hz}$, and $8000 \mathrm{~Hz}$ ) and bone $(500 \mathrm{~Hz}, 1000 \mathrm{~Hz}$,
$2000 \mathrm{~Hz}, 3000 \mathrm{~Hz}$, and $4000 \mathrm{~Hz}$ ). An analysis of audiometry data allowed for the identification of the presence, type, and degree of hearing loss. It also assisted the medical otorhinolaryngologist in determining the causing factor of the loss. Audiometry was carried out using a Siemens audiometer, of the Unity PC model, with HDA 200 headphones and B-71 bone vibrator.

Authors used the World Health Organization (WHO) classification to analyze the degree of hearing loss, which considers the average of $500 \mathrm{~Hz}, 1000 \mathrm{~Hz}, 2000 \mathrm{~Hz}$, and $4000 \mathrm{~Hz}$ frequencies. $^{18}$

Next, the patients underwent acuphenometry, to identify their tinnitus frequency sensation (pitch) and intensity (loudness). During this evaluation, the individual was asked to report what the tinnitus sounded like (whistle, hiss, among others). Then, the examiner presented sounds that could possibly be similar to those described by the patient, among those emitted via audiometer. As soon as the individual was able to identify the sound similar to the tinnitus (pitch), they would raise their hand. Pure-tone or narrow-band noise was presented in each of the frequencies (from $250 \mathrm{~Hz}$ to 8,000 $\mathrm{Hz}), 10 \mathrm{~dB}$ hearing level (dBHL) above the audiometric threshold. As soon as the tinnitus pitch was identified, the signal was presented at $10 \mathrm{dBHL}$ below the hearing threshold, increasing it by $2 \mathrm{dBHL}$ each step and asking the individual to identify the intensity most similar to that of the tinnitus. The examiner performed the procedure separately for each ear, noting the intensity referred to by the individual and subtracting it from the hearing threshold. This calculation allowed for the determination of the intensity of the tinnitus sensation. $^{19}$

At the end of the audiological evaluation, the patient returned to the Otorhinolaryngology sector for a medical consultation to determine the cause of hearing loss and of the tinnitus.

The project was analyzed and approved by the Ethics in Research Committee of the hospital (protocol $n^{\circ}$ 06026), guaranteeing the rights of non-identification, silence, and waiver of participation.

The data collected were stored in a data bank, made in Microsoft Excel ${ }^{\circledR}$, and afterwards, analyzed utilizing the statistical program SPSS (Statistical Package For Social Sciences), version 18.0. Quantitative variables were expressed as mean and standard deviation or median and interquartile range. The qualitative variables were expressed by absolute and relative frequencies. The Wilcoxon test was utilized for the ear comparison. To evaluate the association between the hearing thresholds and age with the acuphenometry, Spearman's rank correlation was applied. It compared the loudness and pitch of the tinnitus with the laterality of the tinnitus and sex with the MannWhitney test. For the comparison between the degrees of loss, the Kruskal-Wallis test was applied. In addition to this, to associate the sex with the laterality of the tinnitus, the chi-squared test was applied. The significance level adopted was of $5 \%$ ( $\mathrm{p} \leq 0.05$ ).

For their research, authors considered the average of tinnitus loudness and pitch, due to the asymmetrical 
Table 1 Analysis of laterality of tinnitus and demographic variables of the sample ( $n=33$ individuals)

\begin{tabular}{|l|l|l|l|}
\hline & Unilateral tinnitus & Bilateral tinnitus & $\mathbf{p}^{*}$ \\
\hline $\begin{array}{l}\text { Age (years): } \\
\text { average } \pm \text { sd }\end{array}$ & $61.7 \pm 9.2$ & $57.8 \pm 9.6$ & 0.249 \\
\hline Gender: $\mathrm{n}(\%)$ & & & \\
\hline Male & $9(60)$ & $13(72.2)$ & 0.711 \\
\hline Female & $6(40)$ & $5(27.8)$ & \\
\hline
\end{tabular}

${ }^{*}$ Chi-square Pearson.

Table 2 Analysis of the influence of the gender variable loudness and pitch of tinnitus ( $n=33$ individuals)

\begin{tabular}{|l|l|l|}
\hline $\begin{array}{l}\text { Female } \\
\text { Median (P25-P75) }\end{array}$ & $\begin{array}{l}\text { Male } \\
\text { Median (P25-P75) }\end{array}$ & $\mathrm{P}^{*}$ \\
\hline Loudness & & 0.190 \\
\hline Rignt ear 20 (6.3-30) & $15(0-20)$ & 0.469 \\
\hline Left ear 15 (6.3-20) & $7.5(5-25)$ & \\
\hline Pitch & & 0.149 \\
\hline Right ear 2500 (500-6000) & $4000(4000-8000)$ & 0.672 \\
\hline Left ear 6000 (3000-7500) & $4000(2250-7500)$ & \\
\hline
\end{tabular}

*Mann-Whitney.

distribution of the data. This average was more effective, since the extreme values of the series did not affect it.

\section{Results}

Thirty-three individuals of both genders participated in the study, of which 11 (33.3\%) were female and 22 (66.7\%) were male, aged between 42 and 76 years (average of $59.5 \pm 9.4$ years). Of these, five (15.1\%) presented tinnitus in the right ear (RE), 10 (30.3\%) in the left ear (LE), and 18 (54.5\%) in both ears. Average hearing loss (from 500 to $4000 \mathrm{~Hz}$ ) was $29.7 \pm 19.9$ in the RE and $23.2 \pm 10.3$ in the LE. For the associations related to the frequency of the highest hearing threshold, as well as tinnitus pitch and loudness, the authors considered only the ears that presented tinnitus, totaling a sample of 51 ears.

- Table 1 presents the results referring to the analysis between the laterality of the tinnitus and the demographic variables of the sample (gender and age). There was no significant difference between the analyzed variables and the laterality of the tinnitus.
-Table 2 demonstrates an analysis of the association between the type variables, loudness, and pitch of the tinnitus. The analysis confirmed that there was no significant relation between gender and the loudness and pitch of the tinnitus.

- Table 3 presents data pertaining to the loudness and pitch of the tinnitus for each ear, solely considering the individuals with bilateral tinnitus. No significant difference was confirmed between the pitch and the loudness of the right and left ears.

The analysis between the highest hearing thresholds and the loudness of the tinnitus is presented in - Fig. 1. It is possible to observe a consistent and significant inverse association between these variables, or, in other words, the greater the loudness of the tinnitus, the lower the intensity of the highest hearing threshold $\left(r_{\mathrm{s}}=-0.411 ; p=0.003\right)$.

-Fig. 2 presents an analysis of the average of the hearing thresholds (from 500 to $4000 \mathrm{~Hz}$ ) and the loudness of the tinnitus. The analysis confirmed that there was a consistent and significant inverse association; therefore, the greater the

Table 3 Analysis of the loudness and pitch of tinnitus in patients with bilateral tinnitus ( $n=36$ ears)

\begin{tabular}{|l|l|l|l|}
\hline & $\begin{array}{l}\text { Right Ear } \\
\text { median } \\
\text { (P25-P75) }\end{array}$ & $\begin{array}{l}\text { Left Ear } \\
\text { median } \\
\text { (P25-P75) }\end{array}$ & ${ }^{*} \mathrm{P}$ \\
\hline Loudness & $15(5-25)$ & $10(5-24)$ & 0.236 \\
\hline Pitch & $4000(2000-8000)$ & $4000(3000-7500)$ & 0.779 \\
\hline
\end{tabular}

*Wilcoxon Test. 


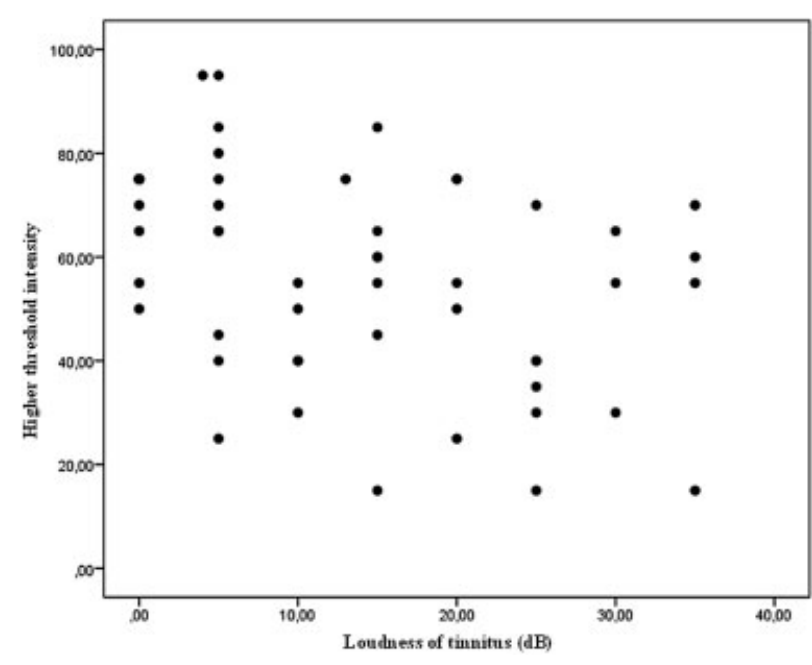

Fig. 1 Tinnitus loudness analysis with the intensity of greater hearing threshold ( $n=51$ ears).

loudness of the tinnitus, the lower the average of the hearing thresholds $\left(\mathrm{r}_{\mathrm{s}}=-0,547 ; p<0.001\right)$.

The data presented in - Fig. 3 represents the analysis of the association between the degree of hearing loss and the loudness of the tinnitus. The analysis confirmed that the higher the degree of hearing loss, the lower the loudness of the tinnitus ( $p=0.005)$.

In analyzing the association between the degree of hearing loss and the pitch of the tinnitus, the authors confirmed that it was not significant $(p=0.316)$. Moreover, the degree of hearing loss did not relate to age in the $\operatorname{RE}(p=0.714)$ or in the $\operatorname{LE}(p=0.165)$.

-Fig. 4 shows an analysis between the frequency of the highest hearing threshold and the pitch of the tinnitus. This analysis confirms that there was no statistically significant association between the variables $\left(r_{s}=0.155 ; p=0.278\right)$.

The authors compared tinnitus loudness and pitch, to determine whether these variables suffered some type of influence from the individualś ages. When age was related to

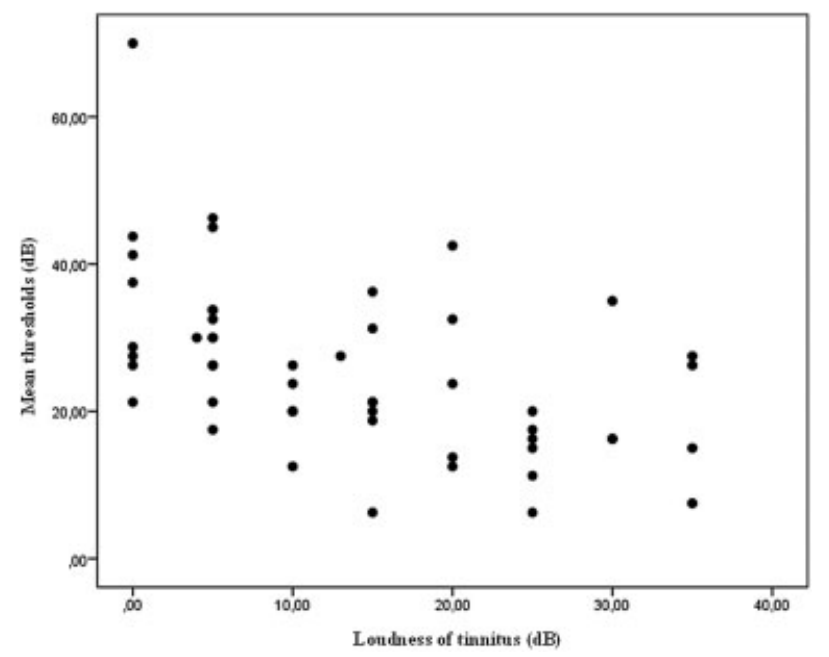

Fig. 2 Analysis between loudness of tinnitus and the mean thresholds $(n=51$ ears).

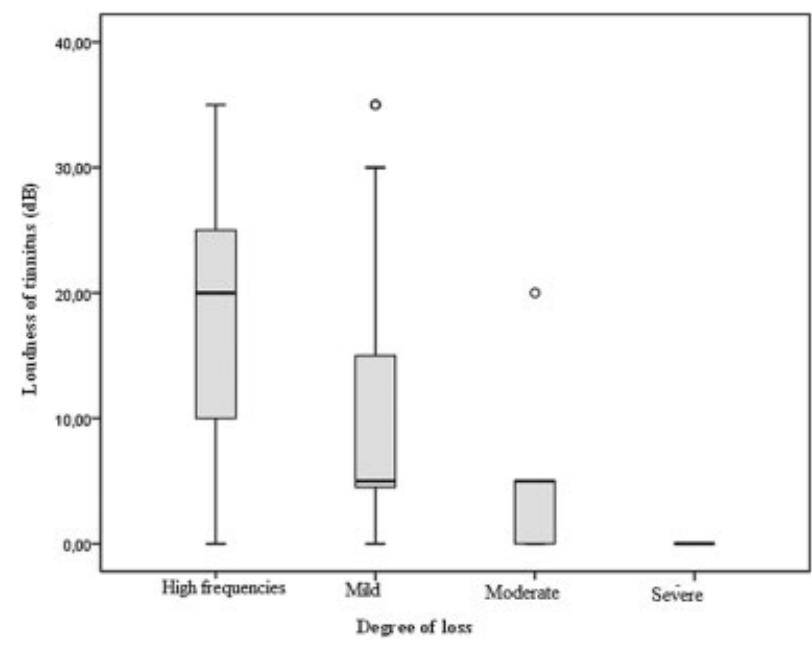

Fig. 3 Loudness of tinnitus as degree of loss ( $n=51$ ears).

loudness of the tinnitus, there was no association in either of the ears $\left(\operatorname{RE~}_{\mathrm{s}}=-0.242 ; p=0.266 ; \mathrm{LE}_{\mathrm{s}}=0.322 ; p=0.095\right)$. The same held true in relation to pitch $\left(R E r_{s}=0.074\right.$; $p=0.738 ;$ LE $_{\mathrm{s}}=0.209 ; p=0.287$ ).

\section{Discussion}

Through this study, the researches confirmed that there was a greater number of male individuals $(66.75 \%)$ compared to female (33.3\%). This result was expected, since previous studies proved that there is a greater number of men working at noisy sites. ${ }^{15,16,18,20-22}$ There was only one study consulted that had a greater prevalence of women, disagreeing with the results obtained. ${ }^{5}$

The age of individuals that composed the sample was between 42 and 76 years old (average of $59.5 \pm 9.4$ years), similar to other studies that analyzed individuals with NIHL. ${ }^{5,17}$ This average differed, however, from another research study on the same theme that used an average age of

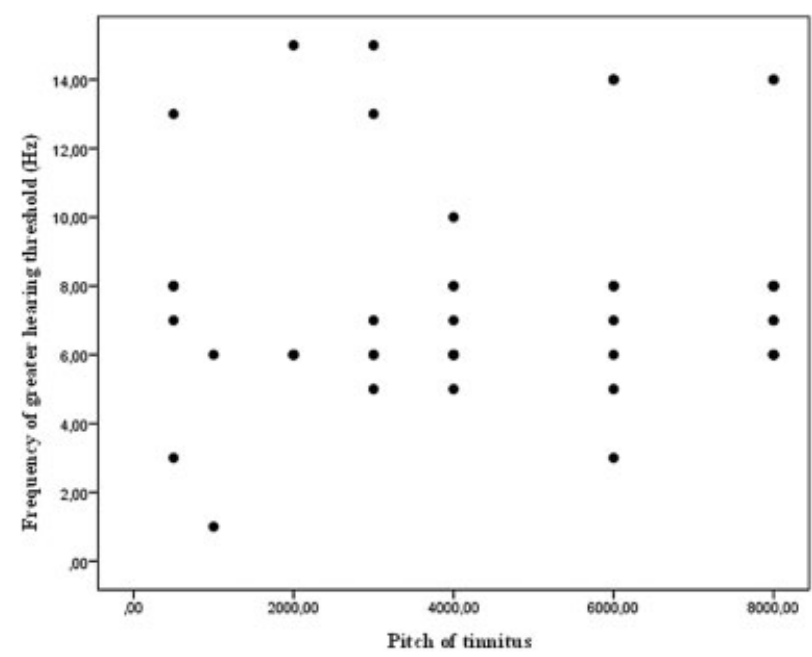

Fig. 4 Tinnitus pitch analysis with greater frequency hearing threshold ( $n=51$ ears). 
39.2 years. $^{14}$ The literature reports greater incidence of tinnitus among 40- and 60-year-olds. ${ }^{23}$ This may explain the elevated average age in the sample evaluated, given that the research study participants were evaluated in the tinnitus outpatient ward.

In that which concerns tinnitus laterality, the study confirms there is a greater number of individuals with bilateral tinnitus (54.5\%), followed by tinnitus in the LE. This data corroborates with other studies performed. ${ }^{14,17}$ The authors believe this result is largely a consequence of the sample evaluated. The sample consisted of individuals with NIHL, a condition characterized by a bilateral otological lesion. This may explain the fact that the majority of cases presented tinnitus in both ears. ${ }^{1,3,4}$ The authors believe that unilateral tinnitus in patients with NIHL is a function of the type of work performed as well as workerś daily exposure to noise in their work environment. ${ }^{5,9,17}$ It is important to note that the presence of tinnitus in all subjects assessed was solely attributed to hearing loss induced by noise.

In relation to the laterality of tinnitus, authors observed that the age and gender variables were not associated with the presence of uni- or bilateral tinnitus. This result confirms a previous finding, based on the assessment of a significant number of individuals, where there were no differences between men and women in tinnitus laterality. ${ }^{5}$

Data analysis on the influence of the gender variable on tinnitus pitch and loudness showed that there was no difference between men and women. The average of loudness for women was 20dBHL in the RE and 15dBHL in the LE, and their pitch average was $2500 \mathrm{~Hz}$ in the RE and $6000 \mathrm{~Hz}$ in the LE; whereas, the loudness average for men was $15 \mathrm{dBHL}$ in the RE and 7.5dBHL in the LE, and their pitch average was $4000 \mathrm{~Hz}$ in both ears. Studies on the psychoacoustics of the tinnitus utilizing the average value were not available, but research based on the mean calculation showed that the pitch in both ears was $6000 \mathrm{~Hz}$. There was no difference between females and males. There was also no difference in the average value of tinnitus loudness between each ear, or between men and women. ${ }^{5}$ It is believed that the result obtained can be attributed to the noise, since exposure to noise is common among individuals with NIHL, causing bilateral effects. ${ }^{4}$

Analyzing only the results of the acuphenometry in the individuals with bilateral tinnitus, the authors did not observe a significant difference between the loudness and the pitch of the tinnitus between both ears. Furthermore, it seems these values receive influence from exposure to elevated levels of sound pressure and particular characteristics of similarity between the ears. ${ }^{22}$

With regards to tinnitus loudness, this study showed a variation of 5 to 25dBNA. A study performed with individuals exposed to occupational noise observed a variation of 0 to 20 dBNA, ${ }^{14}$ a very similar result to that found in our sample components. The average of the pitch was $4000 \mathrm{~Hz}$, which is also described in the studied literature. In other words, there is a prevalence of tinnitus with higher frequencies.

In observing the relation between the loudness of the tinnitus and the intensity of the highest hearing threshold, the authors confirmed an inverse association. In other words, the lower the hearing threshold, the greater the loudness of the tinnitus. This data may support the hypotheses that individuals with well-conserved hearing thresholds present better perception of sound in general, ${ }^{24}$ and, thus, perceive the tinnitus with greater intensity. No studies that relate the intensity of the higher hearing threshold with the loudness of the tinnitus were found.

In the analysis between the loudness of the tinnitus and the average of the hearing thresholds, tinnitus loudness was more prevalent in the ears with a lower hearing threshold average. This finding diverges from the study that found a direct association with the right and left sides. ${ }^{5}$ The authors believe and the literature confirms that the relation between the loudness and the average of the thresholds is direct. However, it is clear that the lowering of the hearing thresholds is not responsible for the increase in the tinnitus sensation, and just as was previously mentioned, can be related to the better perception of this symptom.

In relating the degree of hearing loss with the loudness of the tinnitus, the present study showed that individuals with hearing loss only in high frequencies presented greater tinnitus loudness in acuphenometry. This finding agrees with the literature, which states there is an increase of tinnitus in accordance with increase of hearing loss. ${ }^{9}$ The result found in the present study may be due to the individuals with hearing loss experiencing a deprived capacity to adequately understand sound information, ${ }^{24}$ resulting in a reduced tinnitus sensation.

The authors observed no association between the pitch of the tinnitus and the frequency of the highest hearing threshold, corroborating with one of the studies analyzed. ${ }^{14}$ Another study, however, presented partially disagreeing results. After analyzing tinnitus pitch in 286 patients, the researchers concluded that, for the RE, the pitch of the tinnitus was associated with the frequency of the greatest hearing loss, which was not true in the LE. ${ }^{15}$ They believed these variables could be associated, since the frequency of the highest hearing threshold suffered the greatest influence from noise exposure, and enabled greater predisposition for tinnitus. It should be noted, however, that the data obtained in the research may have been influenced by the size of the sample.

\section{Conclusion}

Data analysis shows that, in the evaluated individuals, the greater the hearing loss, the lower the loudness of tinnitus. We did not observe an association between hearing loss and tinnitus pitch.

\section{References}

1 Mitchell J, Mccombe A. Noise-induced hearing loss. ENT Masterclass 2009;2(1):107-111

2 World Health Organization. Occupational and community noise. Geneva, Switzerland: World Health Organization; 2001. (Fact Sheet 258)

3 Bezerra MD, Marques RA. Configurações audiométricas em saúde ocupacional. RBPS 2004;17(2):61-65 
4 Fiorini AC, Fischer FM. Expostos e não expostos a ruído ocupacional: estudo dos hábitos sonoros, entalhe audiométrico e teste de emissões otoacústicas evocadas por estímulo transiente. Distúrb Comun 2004;16(3):371-383

5 Mazurek B, Olze H, Haupt H, Szczepek AJ. The more the worse: the grade of noise-induced hearing loss associates with the severity of tinnitus. Int J Environ Res Public Health 2010;7(8): 3071-3079

6 Jastreboff PJ. Phantom auditory perception (tinnitus): mechanisms of generation and perception. Neurosci Res 1990;8(4): 221-254

7 Baguley D, McFerran D, Hall D. Tinnitus. Lancet 2013;382(9904): 1600-1607

8 Figueiredo RR, Azevedo AA. Introdução, epidemiologia e classificações. In: Ltda.; 2013:1-4

9 Dias A, Cordeiro R, Corrente JE, Gonçalves CGO. Associação entre perda auditiva induzida pelo ruído e zumbidos. Cad Saude Publica 2006;22(1):63-68

10 Fujii K, Nagata C, Nakamura $\mathrm{K}$, et al. Prevalence of tinnitus in community-dwelling Japanese adults. J Epidemiol 2011;21(4): 299-304

11 Michikawa T, Nishiwaki Y, Kikuchi Y, et al. Prevalence and factors associated with tinnitus: a community-based study of Japanese elders. J Epidemiol 2010;20(4):271-276

12 Folmer RL, McMillan GP, Austin DF, Henry JA. Audiometric thresholds and prevalence of tinnitus among male veterans in the United States: data from the National Health and Nutrition Examination Survey, 1999-2006. J Rehabil Res Dev 2011;48(5):503-516

13 Engdahl B, Krog NH, Kvestad E, Hoffman HJ, Tambs K. Occupation and the risk of bothersome tinnitus: results from a prospective cohort study (HUNT). BMJ Open 2012;2(1):e000512

14 Possani LNA. Estudo da prevalência e das características do zumbido em trabalhadores expostos ao ruído ocupacional [Dissertation]. Porto Alegre, Brazil: Universidade Federal do Rio Grande do Sul; 2006
15 Schecklmann M, Vielsmeier V, Steffens T, Landgrebe M, Langguth B, Kleinjung T. Relationship between Audiometric slope and tinnitus pitch in tinnitus patients: insights into the mechanisms of tinnitus generation. PLOS ONE 2012;7(4):e34878

16 Sereda M, Hall DA, Bosnyak DJ, et al. Re-examining the relationship between audiometric profile and tinnitus pitch. Int J Audiol 2011; 50(5):303-312

17 Nageris BI, Attias J, Raveh E. Test-retest tinnitus characteristics in patients with noise-induced hearing loss. Am J Otolaryngol 2010; 31(3):181-184

18 World Health Organization. Prevention of blindness and deafness: Grades of hearing impairment. Available from: http://www.who. int/pbd/deafness/hearing_impairment_grades/en/. Accessed on April 23, 2015

19 Branco-Barreiro FCA. Avaliação audiológica básica e psicoacústica do zumbido. In: Samelli AG Zumbido: Avaliação, diagnóstico e reabilitação: Abordagens atuais. 1st Ed. São Paulo, Brazil: Lovise; 2004:55-58

20 Lopes AC, Nelli MP, Lauris JRP, Amorim RB, Melo ADP. Condições de saúde auditiva no trabalho: Investigação dos efeitos auditivos em trabalhadores expostos ao ruído ocupacional. Int Arch Otorhinolaryngol 2009;13(1):49-54

21 Harger MRHC, Barbosa-Branco A. Effects on hearing due to the occupational noise exposure of marble industry workers in the Federal District, Brazil. Rev Assoc Med Bras 2004;50(4): 396-399

22 Araújo SA. Perda auditiva induzida pelo ruído em trabalhadores de metalúrgica. Rev Bras Otorrinolaringol 2002;68(1):47-52

23 Sanchez TG, Bento RF, Miniti A, Cârnara J. Zumbido: Características e epidemiologia. Experiência do Hospital das Clínicas da Faculdade de Medicina da Universidade de São Paulo. Rev Bras Otorrinolaringol 1997;63(3):229-235

24 Silman S, Iório MCM, Mizhahi MM, Parra VM. Próteses auditivas: um estudo sobre seu benefício na qualidade de vida de indivíduos portadores de perda auditiva neurossensorial. Distúrb Comum 2004;16(2):153-165 